\title{
D on Catrín de la Fachenda: La ironía como expresión de una normativa vacilante
}

\section{Raúl Marrero-Fente}

Columbia University

\section{Resumen}

Este estudio examina la novela Vida y hechosdeD on Catrín dela Fachenda deJ.J. Fernández de Lizardi. Planteo que la obra de Fernández de Lizardi es más compleja que sus modelos literarios anteriores pues representa una triple marginalidad: social, nacional y literaria. El aspecto innovador de la imitación literaria de su autor se basa en el uso de modelos picarescos para cuestionar - adelantado a su tiempo- los proyectos nacionales de las repúblicas emergentes en América Latina.

Palabras claves: Fernández de Lizardi, catrín, proyecto nacional, ironía, imitación, picaresca.

\section{Abst Ract}

Thisstudy examines thenovel Vida y hechosdeD on C atrín dela Fachenda by J.J. Fernandez de Lizardi. I propose that Fernandez de Lizardi's work is more complex than its previous literary models because it presents a triple marginality: social, national, and literary. The innovative aspect of the author's literary imitation is based upon the use of the picaresque models to question - ahead of his time- the national projects of the emerging republics in Latin America.

KEYwords: Fernández de Lizardi, catrín, M exico, national project, irony, imitation, picaresque.

Recibido: 03.09.2002. Aceptado: 03.12.2002.

A N O VELA Vida y hechos del famoso caballero D on Catrín dela Fachenda ${ }^{1}$ (1832) del escritor mexicano J osé J oaquín Fernández de Lizardi (17761827) relata las aventuras de un pícaro de la sociedad mexicana en el período de transición de la colonia a la Independencia. El texto se presenta

'José J oaquín Fernández de Lizardi. Vida y hechos del famoso caballero D on Catrín dela 
como una memoria inconclusa de la vida de don Catrín, escrita por éste poco antes de su muerte y final izada por el practicante don Cándido, que asistea don C atrín en los últimos momentos de su vida. La novela expone las tesis de don C atrín sobre las ventajas de la vida del pícaro. Estas ideas son criticadas por don Cándido en el capítulo que cierra la obra y en una serie de notas a pie de página. U na primera lectura muestra la diferencia entre las aspiraciones de don C atrín y el resultado de sus acciones. La segunda lectura aparece en las notas a pie de página incluidas por un narrador diferente a don Catrín (el practicante don Cándido) y que ponen en entredicho las acciones y pensamientos del personaje principal. I gual sucede con el capítulo final de la novela redactado por don C ándido y que ataca la imagen que el pícaro don C atrín pretende ofrecer a los lectores, en una especie de testamento del personaje.

La crítica ha insistido en señalar entre las causas de la aparición de esta obra el estado de censura en M éxico durante la época posterior a la restauración de Fernando VII², y la abrogación de la C onstitución de Cádiz de $1812^{3}$. D e ahí el carácter de escritura alternativa de la obra de ficción de Lizardi, nacida ante la imposibilidad dedesempeñar sus tareas periodísticas4. Al respecto comenta Rocío 0 viedo:

D esde el periodismo, quetanta relación guarda con la crónica, surgeel relato de ficción que, como indica el autor, prepara el ánimo de lector y su inclinación hacia la verdad delo narrado. La ficción se convierte, de este modo, en un instrumento al servicio de la política y la sociedad. En este aspecto, la historia marca el devenir literario, así como el transcurso del propio Lizardi. El auge del periodismo viene favorecido por un desarrollo mayor de la imprenta y una clase criolla más activa, que enarbola la pluma como instrumento logístico. Los ilustrados mexicanos ven en el periódico un medio imprescindible para el logro de la independencia y se suceden las publicaciones periódicas, así como las referenciasal tema que será constante en EI Pensador M exicano: la libertad de imprenta (Fernández de Lizardi, 13-14).

Fachenda. Imprenta del ciudadano Alejandro Valdés, M éxico, 1832. La novela fue escrita en 1819, pero no fue publicada hasta 1832, después de la muerte de Lizardi. Todas las citas pertenecen a la edición de Rocío 0 viedo y Almudena M ejías. En lo adelante la obra se cita como D on Catrín. Sobre Lizardi y su obra pueden consultarse los trabajos de Janik, O viedo, Ruiz Barrionuevo, Vogeley, Benítez-Rojo, Salomon, Gilbert, Goic, Alvarez de Testa, C vitanovic, Franco, Reyes Palacios, M oraña, de Alba-Koch, Rea Spell, Borgeson, Bancroft, Beroud, Iñigo M adridgal, Lasarte, Leal, Pawlowski, Van Praag, Yáñez y Ramírez Pimienta.

2Para una exposicion detallada sobre las consecuencias de la restauración en M éxico ver los estudios de Arrangoiz y Teja Z abre. Para el trasfondo histórico de la época es necesario consultar los vols. IV y V de la obra colectiva editada por Bethell.

3Una introducción al trasfondo legal de esta época en Sánchez Agesta, 423-424 y 438-444. Para el contexto latinoamericano del siglo XIX es muy útil Agoglia, 57-73, donde hay un análisis sobre la evolución del pensamiento constitucional y delas doctrinas políticas en América L atina durante el siglo XIX. 
Sin embargo, poco se ha investigado otro aspecto que podemos llamar la conciencia de escritor de Fernández de Lizardi. Especialmente la relación de esta obra con otras novelas y relatos anteriores del mismo autor. Durante el período comprendido entre los años 1816 hasta 1819 hay una revalorización en las concepciones estéticas y en el papel del escritor como figura pública en la sociedad mexicana. Una muestra de la importancia concedida por Fernán dez de Lizardi a su labor narrativa aparece en la "A pología al Periquillo Sarniento", en los debates crítico-literarios sostenidos en la prensa mexican $a^{5}$ y en la referencia explícita en el primer capítulo de D on Catrín, en el que el narrador compara la producción novelística de Fernández de Lizardi:

No, no se gloriará en lo adelantemi compañero y amigo el Periquillo Sarniento de quesu obra halló tan buena acogida en este reino, porque la mía, descargada de episodios inoportunos, de digresiones fastidiosas, de moralidades cansadas, y reducida a un solo tomito en octavo, se hará desde luego más apreciable y más legible: andará no sólo de mano en mano, defaltriquera en faltriquera, y de almohadilla en al mohadilla, sino de ciudad en ciudad, de reino en reino, de nación en nación, y no pararásino después que se hayan hecho de ella mil y mil impresiones en los cuatro ángulos de la tierra (Fernández de Lizardi, 63).

Pero hay una diferencia entre las dos novelas más importantes de Fernández de Lizardi que obedece a una interiorización por el autor de la especificidad de la creación novelística. Esconocido que los paratextos deEI Periquillo Sarniento convierten su lectura en determinados momentos en lenta y trabajosa, un problema que no existe en D on Catrín. Tampoco esa apariencia de "más novela", señalada por varios críticosen relación aD on Catrín (Barcroft, 533-38). Fernández de Lizardi prefiere la narrativa porque no puede desempeñar el periodismo, pero no sabemos por qué escoge este género si escribió poesía anteriormente. La escritura de Lizardi es una forma tangencial de la literatura periodística y cobrará mayor independencia en el propio ejercicio del acto creativo. G eneralmente la crítica ha insistido en las intenciones educativas de los escritos periodísticos lizardianosy en el didactismo de una parte de su producción poética, características atribuidas también a D on C atrín, de ahí su inclusión dentro de los modelos de la novela neoclásica imbuida de principios pedagógicos. La época de la creación de $\mathrm{D}$ on Catrín es un momento de transición en la sociedad mexicana caracterizado por la confusión y el debate entre las diversas facciones en pugna.

${ }^{4}$ Sobre la relación entre el periodismo y la literatura en la obra de Lizardi véanse los trabajos de A. G onzález y de 0 viedo.

"Esta polémicala estudia Vogeley en "T heconcept of "thePeople' in El Periquillo Sarniento", y más recientemente en su libro, Lizardi and the Birth of the N ovel in Spanish America. 
En lo literario, el debate tiene lugar entre las instituciones académicas defensoras de la tradición clásica y neoclásica, frente al mundo literario que se venía gestando en las redacciones de los periódicos, las tertulias y charlas de los cafés más abiertas a los cambios que anunciaban el romanticismo. La base de este conflicto descansa, además, en el proyecto de fundación nacional hispanoamericano nacido como una idea de modernización de las nuevas sociedades soberanas surgidas de la Independencia, y adoptado como propio por el romanticismo hispanoamericano ${ }^{6}$.

En su investigación sobre la picaresca Claudio G uillén menciona la presencia de elementos picarescos en obras cuyos propósitos no eran los de este modelo, y pone como ejemplo el Q uijote de M iguel de Cervantes?. La mayoría de los estudios sobre el EI Periquillo Sarniento analizan lo picaresco y esta circunstancia determinó la inclusión de D on Catrín en este mismo género literario. Entre los trabajos que destacan la presencia de la picaresca en EI Periquillo Sarni ento se destacan, entre otros, los de Catherine Raffi Beroud, N oël Salomon, Jacqueline Van Praag-Chantraine, Luis Leal, Luis Alberto Sánchez y Cedomil Goic. Importantes críticos consideran a D on Catrín como novela picaresca: "D on Catrín atraviesa por las vicisitudes de un héroe de novela picaresca" (Sánchez, 123124); "nacimiento ruin, reconocible en todas las novelas picarescas, incluido el catrín" (Goic, 29); "la creación de prototipos picarescos originales, además del lépero, allí tenemos al catrín" (Leal, 1036); "el carácter pícaro de este personaje" (C asas de Faunce, 58); "picaresca liberal" (Borgeson, 505); "periquillo y catrín son similares en muchas maneras: ambos son miembros de una gran familia picaresca" (Pawlowski, 830); "se aferra don Catrín a su comportamiento 'catrinesco', 0, si sequiere, 'picaresco'" (Lasarte, 104); "próxima por su estructura picaresca al Periquillo" (Iñigo M adrigal, 142). M ención aparte merece la distinción que hace Jefferson Rea Spell, quien reconoce que "la estructura del argumento en El Periquillo y D on Catrín es la que caracteriza a la novela picaresca" - pero aclara"ninguna de las dos, ni el Periquillo ni D on Catrín, nacen del suelo español. Ambas son mexicanas, con todas las características del español pobre desarrollado bajo condiciones coloniales" (Bridging the Gap, 213-215). Entre las opiniones que rechazan el modelo de la picaresca aparecen las de Agustín Yañez: "Su

¿Un amplio panorama de las ideas en I beroamérica durante esta época aparece en los estudios de Gómez M artínez y Chiaromonte.

${ }^{7}$ La cantidad de estudios críticos dedicados a la picaresca es muy extensa y no puedo consi gnarlos todos aquí, sirvan a manera de muestra los trabajos de G uillén, Literature as System. Essays Toward the Theory of Literary H istory. Especialmente el ensayo "Toward a D efinition of the Picaresque". También en su libro, The Anatomies of Roguery: a Comparative Study in the O rigins and the $N$ ature of Picaresque Literature. Casas de Faunce, La novela picaresca latinoamericana. D e consulta imprescindible es Francisco Rico, La novela picaresca y el punto de vista. 
riqueza vital, sus diferencias de contenido y su acoplamiento absoluto con los estilos de vida mexicanos, rechazan el cargo de una imitación picaresca servil"(10); y la de Brushwood: "Sus ideas están firmemente enraizadas en las ideas academicistas del siglo dieciocho, pero su forma de expresión pertenece al pue blo" (56).

Estoy de acuerdo con la tesis de que D on Catrín no es una novela picaresca en sentido estricto como aclaran Felipe Reyes Palacios ("I ntroducción") y Rocío 0 viedo (Fernández de Lizardi, 26), pero sí aparecen en esta novela algunos elementos propios de la picaresca provenientes de la tradición literaria española. También es cierto que la conducta de don Catrín es muy parecida a la del pícaro, en el sentido mencionado por G onzález Echevarría, cuando habla de la vida del pícaro: "La historia de su vida toma la forma de una deposición legal. La picaresca... elaboró el relato de la 'vida' como unidad narrativa imitando una de las fórmulas de la retórica forense, muy popular en aquel entonces: la relación" (La prole de Celestina, 70). El discurso jurídico en D on C atrín es además un eco del debate en torno a la Constitución de Cádiz de 1812. Por eso, a diferencia de las novelas picarescas, no encontramos aquí una deposición ante una autoridad individual, sino ante la sociedad pública, es por lo tanto un discurso legal que busca legitimarse en la Constitución, el texto jurídico más importante de cualquier sociedad moderna. La Constitución de Cádiz de 1812 representó un importante cambio en el ámbito de los derechos individuales: el paso de la condición de súbdito sometido al poder real a la de ciudadano de una república con igualdad jurídica. D urante ese período constitucional Lizardi ejerció sus actividades periodísticas. La abrogación de la Constitución de 1812 y la implantación de la censura en la prensa han sido señaladas como una de las causas de la aparición de esta obra, de ahí se infiere el carácter de escritura alternativa de la novela. Esta escritura paratextual se convierte entonces en escritura al ternativa que desafía el discurso del poder (la afasia de la censura) y seerige ella misma en centro de la obra. Si la verdadera historia es el lenguaje, es decir, cómo hablar/ escribir después de la Independencia, el proyecto de construcción nacional pasa por la escritura.

A proximaciones anteriores $\mathrm{a}$ D on C atrín sólo han tenido en cuenta las relaciones irónicas entrelos personajes narradores don C atrín y don Cándido. Como señala Rocío 0 viedo hay una relación entre ironía y didactismo en esta novela: "En el caso de don Catrín, el propósito didáctico nos lo ofrece a través de la ironía y del sentido paradójico. Paradoja e ironía cuyo efecto es el distanciamiento y que se expresa desde la aparente finalidad de la obra" (Fernández de Lizardi, 28). Pero en la novela existen otras dimensiones irónicas adicionales que podemos explorar. En D on Catrín coexisten dos niveles diferentes de ironía (M uecke, 19), la ironía el emental, que aparece en los resultados de la conducta 
del personaje principal, especie de libertino, pícaro y marginal propio de la sociedad mexicana de la época porque el personaje de don Catrín es realmente una víctima irónica entre lo que expresa como intención o deseo y lo que alcanza con sus acciones. También pertenecen a este nivel las notas a pie de página, incluidas por un narrador diferentea don Catrín y queacotan en sentido opuesto las acciones y pensamientos del personaje principal. I gual función tiene el capítulo final dela novela, contradiscurso que desdobla la falsa imagen que don Catrín nos quiere ofrecer de sí mismo, mostrándolo en su imagen real. Una lectura más detenida nos lleva hasta el nivel elevado de la ironía expuesto en las alusiones y referencias literarias inscritas en la red de citas. Este tipo de ironía es más elaborada. La relación entre los dos niveles se manifiesta como "contradicción, incongruencia o incompatibilidad" (M uecke, 20). En nuestra lectura proponemos analizar la oposición entre estos dos niveles para entender las conclusiones derivadas de la cita de M aquiavelo que le confiere la dimensión más significativa a la novela, su ambigüedad y el carácter vacilante de la escritura. Recordemos que el decálogo de M aquiavelo lo escribe don Catrín dentro del capítulo IX y es una de las abundantes falsificaciones de la teoría del pensador político italiano:

\section{DECÁlOgO de M AQUIAVELO}

1. En lo exterior trata a todos con agrado, aunque no ames a ninguno.

2. Sé muy liberal en dar honores y títulos a todos, y alaba a cualquiera.

3. Si lograres un buen empleo, sirve en él sólo a los poderosos.

4. Aúlla con los lobos. (Esto es, acomódate a seguir el carácter del quete convenga, aunque sea en lo más criminal.)

5. Si oyeres que al guno miente en favor tuyo, confirma su mentira con la cabeza.

6. Si has hecho algo que no te importe decir, niégalo.

7. Escribe las injurias que te hagan en pedernal y los beneficios en polvo.

8. A quien trates de engañar, engáñale hasta el fin, pues para nada necesitas su amistad.

9. Promete mucho y cumple poco.

10. Sé siempretu prójimo tú mismo y no tengas cuidado de los demás (Fernández de Lizardi, 117).

El falso decálogo puede ser leído como una burla irónica de don C atrín, 0 aceptar la tesis de que él no sabe que es falso y por su ignorancia lo incluye porque necesita una autoridad que legitime sus acciones. Aunque es másimportante la nota apócrifa que aparece a pie de página del decálogo: "N icolás M aquiavelo, astuto escribano de Florencia, y después un falso político de Francia, escribió a sus sectarios este maldito decálogo, que trae Alberto $M$ agno en el prefacio de su obra titulada: Bonus politicus, etc." (Fernández de Lizardi, 117). Al tratar de subvertir el orden cronológico de la historia, la historicidad vista 
como anti-historicidad, el practicantedon Cándido - autor de la nota apócrifase muestra realmente como es, un espíritu volteriano que se burla de todas las convenciones, incluso las del discurso más importante de la I lustración. El discurso de don Cándido parodia la obrall Principe(1513) de N iccolo M achiavelli (1469-1527) porque atribuye al político italiano un decálogo que nunca escribió. La inclusión de Alberto M agnus (1206-1280), a quien no sólo se trata de relacionar con $M$ achiavelli (confiriéndole la autoría de un libro que nunca escribió -Bonus politicus-) es más significativa porque el D octor U niversalis fue la figura más importante de la escolástica en el siglo XIII. La presencia de Alberto $M$ agno tiene además un significado muy especial en el caso del N uevo M undo, como recuerda Zum Felde:

... de las grandes épocas históricas en que, de modo general, puede dividirse la Escolástica, del siglo XI al XII y del XIII al XV (en España hasta el XVIII), la primera de predominantes influjos platónicos y agustinianos, la segunda desde Alberto M agno y Santo Tomás, de neta y ya definitiva ideación aristotélica, la que llega a América en el siglo XVI, con la Conquista, es ésta, con exclusión y aún condena de aquellas primeras formas más antiguas; y aún podría precisarse que en una tercera modalidad, la especial mente española y jesuítica, la suareziana, que es fundamentalmente tomística pero retocada, de acuerdo con los tiempos de la contrarreforma en que se produce, y cuya vigencia dura casi los tres siglos de la cultura colonial, hasta la llegada de la Enciclopedia (64).

También explica la descripción irónica que apareceen la novela de los métodos anticuados de enseñanza de la filosofía, en especial la escolástica: "Una ocasión, arguyendo con un rancio peripatético que defendía la existencia de cierto animal Ilamado entresus antiguos patronos 'entede razón' (Fernández de Lizardi, 68). Aunque la escena que sigue nos hace reírnos del latín macarrónico de don Catrín y sus condiscípulos, el ataque a la escolástica, por medio de la ironía, ya ha quedado unido a la condena a los estudios manualescos del latín. Es necesario referirnos a los antecedentes inmediatos dela época para entender la relevancia de estas críticas. En el estudio de Rea Spell sobre las influencias intelectuales en Fernández de Lizardi aparece un resumen de ese momento:

Duranteel siglo dieciocho, el escolasticismo comenzó a perder apoyo en España y en sus dominios. En la primera, Feijoo, M acanaz, Tosca, Foronda y otros heterodoxos, como los Ilamó M enéndez y Pelayo, encabezaron el ataque contra el viejo sistema. U na contrapartida de esta misma batalla tuvo lugar en M éxico, donde se encontraban destacados defensores del progeso como Juan Benito Díaz de Gamarra, autor de Recentioris Philosophia (M éxico, 1774), y el científico José Antonio Alzate, editor de la Gaceta de Literatura (1788-95), en la cual puede seguirse la guerra entre los aristotélicos y los modernos... Lizardi lamenta el tiempo perdido en estas disputas de lógica sin propósitos, y ridiculiza su terminología -cual idades ocultas, ente de razón..." ("The Intellectual Background”, 415). 
D etrás de estas disputas se gestaba un importante cambio en el cuadro teórico de los filósofos mexicanos. Como explica Leopoldo Zea, durante la parte final del dominio colonial español hay una evolución en las ideas sobre las ciencias en M éxico. Este nuevo cambio en el paradigma sustituye las ideas escolásticas por la experiencia (L as ideas en I beroamérica, 12-13). 0 tra importante consecuencia se deriva del estudio de las escuelas filosóficas ajenas a la escolástica, de acuerdo a Zea es una renovación producto del estudio de las ideas

de D escartes, Gassendi, Condillac, N ewton y Locke que abrían brecha entre los propios hombres de la I glesia, preparó la mente de los mexicanos para entender a losfilósofos de la Revolución Francesa. Establecida la capacidad dela razón humana, el hombrey sus derechos habían de ser lostemas discutidos por la intelectualidad mexicana. La revolución filosófica conducía a la revolución política (La filosofía en M éxico, 21).

D on Catrín es una obra de ironía evidente ${ }^{8}$ porque en una primera lectura los detalles irónicos son reconocibles en las escenas de la escuela y la enseñanza del latín y la filosofía, en los diálogos con el tío cura, las alusiones al origen noble de don Catrín, el capítulo final, y el soneto-epitafio. La ironía es evidente en la contradicción entre el discurso de don Catrín y su vida. Pero en la novela funciona una ironía oculta detrás del discurso del personaje don Cándido el practicante, quien pretende ser el contrabalance racional frente a don Catrín, pero es víctima de su actuar crédulo y excesi vamente confiado, simplón e ingenuo. El practicante don Cándido, en su ingenuidad aparente, dice criticar a don Catrín, pero al provocar el juego de las al usiones interminables con la cita apócrifa introduce una ambigüedad en la obra. Esta ambigüedad engendra una fractura irónica entre lo que expresa don Cándido y lo que sugiere la lectura de la nota marginal comentada. La ambigüedad es también parte del modo impersonal dela ironía (M uecke, 53), y en la novela es la consecuencia más importante derivada de las contradicciones entre los discursos que se entrelazan en la misma a partir de un juego de tensiones, exclusiones y confrontaciones mutuas. La ambigüedad del texto nace de la conciencia del carácter conflictivo de la realidad que intenta describir y se pone de manifiesto a través de la ironía como conciencia del espacio que media entre lo que se sueña y la realidad, entre la realidad y el deseo. En D on Catrín aparecen indicios de distanciamiento irónico

${ }^{8}$ M uecke ha dividido la ironía en tres grados y cuatro modos. Los grados reflejan la magnitud en que el sentido verdadero de la ironía es encubierto. Los modos se refieren a la relación entre el sujeto que realiza la ironía y la escena irónica. Así, de acuerdo al grado tenemos ironía evidente, encubierta y privada; y de acuerdo al modo la ironía ingenua, autodespreciativa y dramatizada (53). 
a través del juego de las alusiones. Es un texto autoconsciente con una voluntad de ruptura de los cánones de textos anteriores - particularmente El Periquillo Sarniento. Este deseo de ruptura es una al egoría del anhelo por terminar con las estructuras coloniales. Por otra parte, en la novela se percibe irónicamente la vanidad del proyecto futuro de fundación nacional en la voz del discurso de la convencionalidad del practicante, enfrentado al discurso de la locura catrinesca. Ambas posturas son desacralizadas a partir de las alusiones irónicas apuntadas, ironía que conduce a la ambigüedad al desencadenar un juego ininterrumpido de alusiones, citas, contracitas y refutaciones que siembran en el texto diferentes y contrapuestas respuestas e interpretaciones. Esta ambivalencia obedece a la apropiación y ruptura de la tradición literaria clásica, re-escrita desde la perspectiva de los discursos filosóficos y literarios de la llustracion, y de la narrativa picaresca y cervantina queel texto poneen evidencia. La ambigüedad es además consecuencia del espacio de tensión engendrado. La tensión que ostenta la escritura se manifiesta como normativa vacilante de ansiedad clasificatoria, determinada por formas discursivas no literarias, como el discurso de las ciencias naturales ${ }^{9}$. La descripción de diferentes tipos y caracteres en la sociedad mexicana es una técnica que proviene de los diarios de viajes, de los catálogosy de otras formas de archivos (como los legales), a través de la escritura notarial. C lasificar, reunir y explicar es la razón fundamental del discurso científico del siglo XIX, considerado el discurso hegemónico (González Echevarría. M ito yarchivo, 141). Pero el afán por clasificar en la novela de Lizardi tiene además otra "densidad discursiva" (Roig, 129), porque el momento en que se escribe esta novela es uno de los más convulsos de la sociedad mexicana: representa el tránsito del dominio colonial español a la independencia, y el ascenso de la elite criolla, como recuerda Carmen Ruiz Barrionuevo ("Introducción"). En su carácter de sociedad colonial, la mexicana también estaba sometida a las restricciones de la metropóli. D eahí la vision del mundo de los catrines, las prostitutas, los ladrones, que el texto exhibe como galería de tipos marginales de la población mexicana y que nunca muestra como españoles. Frente a este intento de control aparece en el texto la ironía impersonal (M uecke, 86) quefunciona como crítica a la sociedad colonial. Así podemos ver a lo largo de la obra el elogio decualidades indeseables, como las prerrogativas libertinas de los militares (el ejército colonial), y de la vida licenciosa. 0 tra forma es el elogio inapropiado o irreve rente en el capítulo VIII en defensa de la catrinería, en el pasaje del diálogo entre el protagonista y el eclesiástico:

${ }^{9} \mathrm{Q}$ uiero dejar consignada aquí mi deuda con el espléndido artículo de $\mathrm{D}$ ieter Janik dedicado al Periquillo Sarniento, en el que propone la condición de normativa vacilante para la obra de Fernández de Lizardi. 
- Los catrines, respondí yo, no puede ser, padre mío; porque los catrines son hombres de bien, hombres decentes y, sobre todo, nobles y caballeros. Ellos honran las sociedades con su presencia, al egran las mesas con sus dichos, divierten las tertulias con sus gracias, edifican a las niñas con su doctrina, enseñan a los idiotas con su erudición, hacen circular el dinero de los avaros con su viveza, aumentan la población en cuanto pueden, sostienen el ilustre de sus ascendientes con su conducta y, por último, donde ellos están, no hay tristeza, superstición o fanatismo, porque son marciales, corrientes y despreocupados (111).

M ás importante es la ironía por analogía que aparece en el capítulo XI, cuando critica a la nobleza en otro país (Cuba) para distanciar las consecuencias de la crítica en M éxico. Un enjuiciamiento negativo dirigido al problema clave en la novela sobre los orígenes de la legitimidad de la nobleza, a través de los papeles de don Catrín. En este capítulo es donde la novela se aleja más de la sociedad mexicana. Primero sitúa a don Catrín como noble y después lo ubica en un país extranjero. La escena es interesante porque es la única vez que don Catrín se dirige a la autoridad directamente, solicitando su legitimación, su existencia dentro de la sociedad con un estatuto determinado que lo saque de la marginalidad donde se encuentra. Al margen del margen, desclasado, encarcelado y desterrado. La respuesta de la autoridad no deja lugar a dudas:

N o obstante, puse al gobernador un escrito quejándome de los malos tratamientos de aquel caribe, al egándole mi notoria nobleza y presentándole mis ejecutorias y papeles. Pero como la fortuna se complace en abatir a los ilustres y perseguir la inocencia, el señor gobernador no sólo no me hizo justicia, sino que me exasperó con el decreto siguiente:

La nobleza se acredita con buena conducta mejor que con papeles. Sufra esta parte sus trabajos como pueda, pues un ladrón ni es noble, ni merece ser tratado de mejor modo (130).

D on Catrín no es sólo un pícaro como sus antecesores literarios españoles, es un personaje más complejo porque representa una marginalidad triple: social (lépero), nacional (colonizado) y literaria (imitación). En lo social está junto a los indios en el estamento más bajo, de ahí esa desesperación por intentar tener una apariencia similar a la de las clases al tas. No deja de ser significativo el uso de afeites, vestidos y toda clase de indumentaria para tratar de copiar el modo y estilo de vida de la nobleza y burguesía criollas. Pero el catrín, a diferencia de los otros personajes, no es aceptado por las instituciones más poderosas de la sociedad: el ejército y la Iglesia. Su economía está fuera de la ley, de ahí todas las aventuras en las que se ve envuel to para poder sobrevivir, y que culminan en su encarcelamiento y posterior marginal idad definitiva como mendigo. El paso de la condición demarginado temporal ala demarginal leacompaña hasta la muerte, 
y su carácter irreversible es un signo pesimista importante. Frente a esta circunstancia el texto responde con la manera irónica (M uecke, 77), que es la exageración en los modales urbanos, o el uso excesivo de las fuentes literarias clásicas (uno de los elementos más reiterados en la novela), de ahí la gran cantidad de nombres de autores clásicos y modernos de variadas culturas y lenguas. No todos son tratados del mismo modo ni sometidos al mismo grado de ironía. U no de los primeros comentarios irónicos en la novela es a Jerónimo Ripalda, autor del Catecismo y exposición breve de la doctrina cristiana (1591). Es necesario señalar - como hace Rea Spell- queFernández de Lizardi consideraba erróneas las ideas de Ripalda, contra las que escribió en 1827 un artículo titulado "D udas acerca del catecismo de Ripalda" (418). En los inicios de la obra, don Catrín dice que nació "de padresilustres como de César" y luego confiesa que en realidad no conoce quién es su verdadero padre, pero insiste en un supuesto origen noble, irónicamente se hace eco de las críticas a la nobleza de José C adalso en Cartas marruecas, y del Padre Feijoo en Teatro crítico universal (esta última incluida por don C atrín en su lista de lecturas en el capítulo II de la novela). Pero también es una manera irónica de tratar un libro muy usado anteriormente, el Grand dictionai re historique, ou M elange curieux de l'histoi re sacree et profane de Luis M oreri, fuente principal de Fernández de Lizardi para la mayoría de sus citas y alusiones a personajes y hechos históricos (Spell, 419).

En lo nacional la condición de colonizado le impone a don Catrín la reproducción del modelo colonial en la que su papel está definido como imitador de un sistema (de las elites criollas) que a su vez copia otro modo de vida (el de la nobleza española), por eso el rechazo al trabajo y a otras formas de conducta que desentonan con los códigos de la aristocracia (Palazón, 159-172; G ilbert, 3946). La marginación nacional se agrega a la marginación social. En lo literario la reproducción es a partir de las obras anteriores (la novela picaresca y cervantina), expresado por medio de la escritura que en su complejo de reglas gramaticales delimita el discurso, lo encierra y convierte en una repetición de signos ortográficos conocidos, cuyo significado en última instancia está definido por la autoridad de la lengua (la Real Academia) a través de sus cuerpos de codificación (diccionarios, manuales de ortografía). D on Catrín es un texto que tiene otras obras cercanas -incluso del mismo autor-, que se constituyen en modelos literarios. Pero, en última instancia, apela a la literatura peninsular por medio del sistema de signos de la lengua. El narrador es consciente de esta limitación, no en vano dice don Catrín en el capítulo final que no recuerda si leyó una cita en latín en un obra de Cicerón o de N ebrija: "El ánimo afligido no está a propósito para desempeñar susfunciones, según dijo Cicerón o Antonio de N ebrija, donde únicamente he leído esta sentencia" (Fernández de Lizardi, 142). La ironía no es sólo hacia los clásicos latinos, demuestra además un trato irónico hacia las 
autoridades de la lengua por la referencia a Antonio de N ebrija, autor del Arte de la lengua castellana, la primera gramática del idioma español. El texto llega a los límites posibles porque cuestiona las bases mismas del idioma que origina su escritura. No distinguir intencionalmente la autoridad del idioma es desconocerla. La rebeldía ha estallado también en el ámbito dela lengua, de ahí el uso de mejicanismos y el propio título de la novela. Don Cándido quiere presentarse como la contrapartida del catrín marginal, pero comprende que no pasa de ser un pastiche de $C$ andide, una falsificación inscrita en el margen deotra literatura nacional. El único lugar de la página para la cita apócrifa es la nota marginal, fuera del texto central, acaso para no ser leída nunca.

En la novela de Fernández de Lizardi encontramos situaciones irónicas que proponen un dilema a resolver (M uecke, 114). Esta paradoja en la novela es resultado de las acciones de don Catrín conducentes a resultados opuestos a los que anuncian, y de las palabras de don Cándido que nos llevan a un entendimiento distinto del declarado originalmente. El enigma está planteado en la doble articulación irónica de los diálogos de los personajes principales que tienen sentido contrario. Por la magnitud del sistema de relaciones irónicas entrelazadas en los diálogos de don Catrín y don Cándido se crea una ambigüedad que nos remite a códigos infinitos que, en última instancia, no podemos desentrañar. En la relación don Catrín/don Cándido se confunden los discursos irónicos en un juego de alternancias imposibles de desvelar por la ambigüedad de la escritura que vacila y se afirma a la misma vez en un juego de alusiones interminables.

\section{OBRAS CITADAS}

Agoglia, Rodolfo M ario. 1986. "La fundamentación jurídica dela sociedad y el estado", El pensamiento latinoamericano en el siglo XIX. Instituto Panamericano de Geografía e $\mathrm{H}$ istoria.

Alba-Koch, Beatriz de. 2000. "'Enlightened Absolutism' and U topian T hought: Fernández de Lizardi and Reform in N ew Spain". Revista Canadiense de Estudios H ispánicos 24: 295-306.

Alvarez de Testa, Lilian. 1994. Ilustración, educación e independencia. Lasideas de José Joaquín Fernández de Lizardi. U N AM , M éxico.

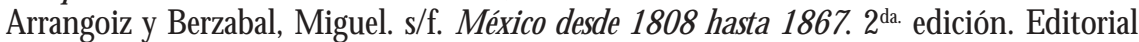
Porrúa, M éxico.

Benítez-Rojo, Antonio. 1999. "José Joaquín Fernández de Lizardi and the Emergence of the Spanish American N ovel as N ational Project". En D oris Sommer (ed. and introd.), The Places of History: Regionalism Revisited in Latin America. Duke University Press, D urham, N C, 199-213.

Bethell, Leslie (ed.). 1985, 1986. The Cambridge H istory of Latin America. Vols. III, IV. C ambridge University Press, Cambridge. 
Borgeson, Paul. 1986. "Problemas detécnicas narrativasen dosnovelas de Lizardi”. H ispania 69, 504-511.

Bancroft, Robert. 1968. "El Periquillo Sarniento and D on Catrín de la Fachenda: W hich is the M asterpiece?" Revista H ispánica M oderna XXXIV: 533-538.

Beroud, CatherineR. 1974. "La picaresca como la única posibilidad literaria o el Periquillo Sarniento". En La picaresca. O rígenes, textos y estructuras. Actas del I C ongreso Internacional sobrela picaresca organizado por el Patronato "Arcipreste deH ita". D irección M anuel Criado de Val. Fundación U niversitaria Española, M adrid.

Brushwood, John S. 1966. M exico in its N ovel. A N ation's Search for I dentity. University of Texas Press.

Casas de Faunce, M aría. 1977. La novela picaresca latinoamericana. Cupsa Editorial, Madrid.

C vitanovic, D inko. 1990. "La al egoría satírica en D on Catrín dela Fachenda". Boletín dela Real Academia Española 70: 301-316.

Chiaromonte, José Carlos. 1979. Pensami ento de la Ilustración. E conomía y soci edad iberoamericanas en el siglo XVIII. Biblioteca Ayacucho, Caracas.

Fernández de Lizardi, José Joaquín. 2001. D on Catrín de la Fachenda. N oches tristes y día alegre. Eds. Rocío 0 viedo y Almudena M ejías. C átedra, M adrid.

Barrionuevo. Cátedra, M adrid.

Franco, Jean. 1983. "La heterogeneidad peligrosa: Escritura y control social en vísperas de la independencia mexicana". H ispamerica 12: 3-34.

Gilbert, William. 1995. "El D on Catrín de Lizardi: Alegoría del Imperio español". Romance Review 5:1: 39-46.

G oic, C edomil. 1972. H istoria de la novela hispanoamericana. Universidad de Valparaíso, Valparaíso, Chile.

Gómez M artínez, José Luis. 1987. "Pensamiento hispanoamericano del siglo XIX". H istoria de la literatura hispanoamericana. Ed. Luis Iñigo Madrigal. Tomo II. Cátedra, M adrid, 399-407.

González, Aníbal. 1993. "Journalism and (dis)simulation in El Periquillo Sarniento". Journalism and the development of Spanish American narrative. Cambridge University Press, Cambridge, 21-41.

González Echevarría, Roberto. 1999. "La vida y aventuras de Cipión. Cervantes y la picaresca". La prole de Celestina. Continuidades del barroco en las literaturas españolas e hispanoamericana. Colibrí, M adrid.

cana. Fondo de Cultura Económica, M éxico.

G uillén, C laudio. 1971. Literature as System. Essays Toward theT heory of Literary H istory. Princeton University Press, Princeton, N.J.

- - - - 1987. The Anatomies of Roguery: a C omparative Study in the 0 riginsand the N ature of Picaresque Literature. N ew York: Garland.

Iñigo M adrigal, Luis. 1987. "José J oaquín Fernández de Lizardi". H istoria dela literatura hispanoamericana. Tomo II. Cátedra, M adrid.

Janik, D ieter. 1987. “El Periquillo Sarni ento de J. J. Fernández de Lizardi: U na normativa vacilante (sociedad-naturaleza y religión-razón)". I bero-Americanisches Archiv: 49-60.

Lasarte, Pedro. 1989. "D on C atrín, D on Q uijote y la picaresca”. Revista deEstudios H ispánicos 23: 101-112. 
Leal, Luis. "Pícaros y léperos en la narrativa mexicana". En La picaresca. O rígenes, textosy estructuras. Actas de I C ongreso Internacional sobre la picaresca organizado por el Patronato "Arcipreste de H ita". D irección M anuel Criado de Val. Fundación Universitaria Española, M adrid.

M oraña, M abel. 1989. "El Periquillo Sarniento y la ciudad letrada". Revista de Estudios H ispánicos 23: 113-126.

M uecke, D ouglas C. 1969. The C ompass of I rony. M ethuen, L ondon.

O viedo, Rocío. 1982. La obra de José Joaquín Fernández de Lizardi. Prosa periodística. Universidad Complutense, Madrid, 2 vols.

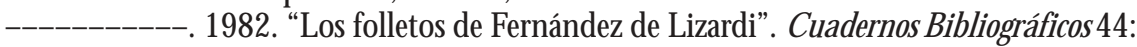
123-134.

- - - - . 1982. "Una obra puente entre el periodismo y la novela de Fernández de Lizardi". Boletín M illares Carlo, Las Palmas de Gran Canaria, III : 39-65.

- - - - - - - . 1984. "El panfletismo de Fernández de Lizardi a través del estudio de uno de susfolletos". M emoria del XX C ongreso del Instituto Internacional de Literatura I beroamericana. Universidad Eotvos Lorand, Budapest, 339-351.

Palazón M ayoral, M aría Rosa. 1991. "La nobleza pícara o D on Catrín de la Fachenda". Nuevo Texto Crítico 4: 159-172.

Pawlowski, John. 1975. "'Periquillo' and 'C atrin': comparison and contrast”. H ispania 58: 830-842.

Ramírez Pimienta, Juan Carlos. 1998. "Picaresca mexicana: El Periquillo Sarniento en el tejido mental de la nación". Revista H ispánica M oderna: 225-35.

Rea Spell, J efferson. 1971. "The Literary Work of Lizardi". Bridging the Gap: Articles on M exican Literature. Editorial de Libros de M éxico, M éxico.

-.--1956. "The Intellectual Background of Lizardi as Reflected in El Periquillo Sarniento". PM LA LXXXI: 414-432.

Reyes Palacios, Felipe. 1999. "Fernández de Lizardi antes del Periquillo". Literatura M exicana $10: 35-67$.

--_.--1990. "Prólogo" a la edición de osé Fernández de Lizardi, O bras. Tomo IX. UNAM, M éxico.

Rico, Francisco. 2000. La novela picaresca y el punto de vista. Seix Barral, Barcelona.

Ruiz Barrionuevo, Carmen. 1988. "La cultura ilustrada de José Joaquín Fernández de Lizardi". Suplemento de Anuario de Estudios Americanos, H istoriografía y Bibliografía XLVIII : 75-94.

problemas textuales de las cuatro primeras ediciones". Siglo D iecinueve 2: 147-162.

Salomon, N oël. 1965. "La crítica del Sistema Colonial dela N ueva España en El Periquillo Sarniento". CuadernosAmericanos 138: 166-179.

Sánchez Agesta, Luis. 1976. Curso de D erecho Constitucional Comparado. Universidad de $M$ adrid, M adrid.

Sánchez, Luis Alberto. 1953. Proceso y contenido de la novela hispanoamericana. Editorial Gredos, M adrid.

Teja Zabre, Alfonso. 1935. Guideto theH istory of M exi co. A modern interpretation. Press of the M inistry of Foreing Affairs, M exico.

Van Praag-Chantraine, Jacqueline. 1974. "El Periquillo Sarniento: un pícaro criollo". En La picaresca. O rígenes, textos y estructuras. Actas del I Congreso Internacional sobre la 
pi caresca organizado por el Patronato "Arcipreste de H ita”. D irección M anuel Criado de Val. Fundación Universitaria Española, M adrid.

Vogeley, Nancy. 2001. Lizardi and the Birth of the Novel in Spanish America. University Press of Florida, Gainesville.

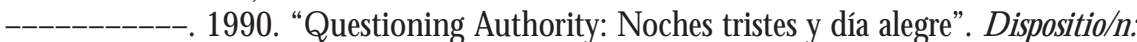

American Journal of Cultural H istories and Theories 40: 53-70.

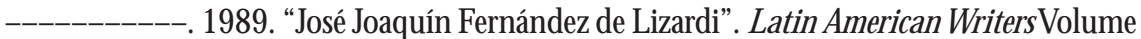

I. N ew York: Charles Scribner's Sons.

- 102: $784-800$.

- 70: $457-465$.

Yáñez, Agustín. 1962. "Estudio Preliminar". El Pensador M exicano. UN AM , M éxico.

Zea, Leopoldo. 1956. Lasideasen Iberoamérica en el siglo XIX. U niversidad Nacional deLa

Plata, La Plata.

--.- 1955. La filosofía en M éxico. Tomo I. Biblioteca M ínima M exicana, M éxico. Zum Felde, Alberto. 1954. Indice crítico de la literatura hispanoamericana. Los ensayistas. Editorial Guarania, M éxico. 